\title{
Dynamic loading in monitoring of brittle objects by acoustic emission method
}

\author{
Artem Popkov ${ }^{1, *}$, and Anton Kochetkov ${ }^{1}$ \\ ${ }^{1}$ Siberian Transport University, 630049 Novosibirsk, Russia
}

\begin{abstract}
Acoustic emission monitoring requires applying a force to an object. In most cases, special-purpose loading devices are used for this process; however, they are subject to some operational limitations. Dynamic loading of a controlled object makes it unnecessary to use loading devices and put the object out of operation. The purpose of the study is to develop a technique of acoustic emission monitoring under dynamic loading. The paper describes results of experiments with impact loading of a glass sheet with a crack. It proposes a method for separating the total flow of acoustic emission signals into stationary groups that are typical for different acoustic emission sources.
\end{abstract}

\section{Introduction}

The capability to selectively detect defects developing under load is traditionally considered to be one of the key advantages of acoustic emission monitoring [1-3]. The acoustic emission method may provide the best results in testing brittle materials, in which risks of defects are more dependent on the stress concentration factor than on sizes. In this case, loading is a complex process aimed at bringing the material to the stress state that provokes the development of defects, while preventing the structure from complete destruction. Pressure vessels and apparatuses are controlled through hydraulic or pneumatic tests [4]. Stress-strain state of parts, assemblies and structural elements is created with specialpurpose loading devices [5]. When monitoring structures under dynamic loads, creating conditions for defect development is a non-trivial problem. Impact loading, which can locally reproduce a high level of mechanical stresses and strains, is a promising solution to this problem.

Acoustic emission patterns associated with elastic impact are detailed in [6,7]. However, as related to the detection of emerging defects, acoustic emission, which accompanies crack propagation processes after damping of oscillations, is of more practical interest. The resulting regularities serve as the basis for creating monitoring systems for objects operating under dynamic or impact loads [8].

The paper is aimed at creating a technique for detecting cracks in brittle materials loaded with an elastic impact using the acoustic emission method.

\footnotetext{
*Corresponding author: zabagy@gmail.com
} 


\section{Research Methods}

Experimental studies were carried out on a $3-\mathrm{mm}$ thick glass sheet with dimensions of $200 \times 300 \mathrm{~mm}$ (Fig. 1). The sample was placed horizontally on damping pads [9]. Impacts with steel balls of $12 \mathrm{~mm}$ in diameter and weighing $7 \mathrm{~g}$, freely falling from a height of $1 \mathrm{~m}$, were used for loading the sample. The direction and location of each impact was chosen in such a way as to prevent repeated impact of the ball on the sample after the first rebound [10]. An 8-mm long crack opposite the long edge of the sheet was used as an artificial defect.

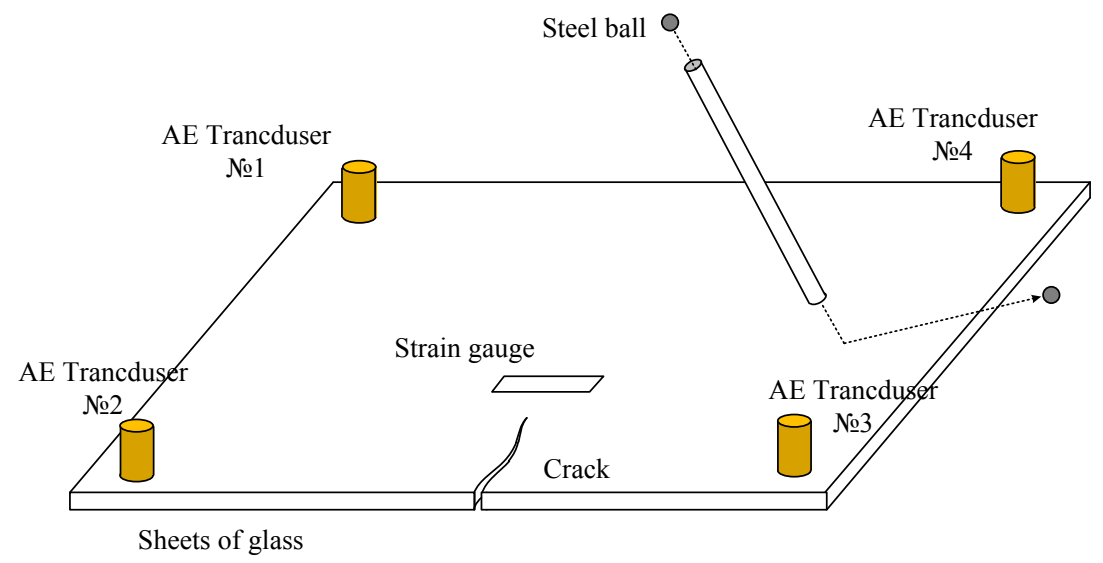

Fig. 1. Experimental scheme.

Acoustic emission signals were recorded by a digital acoustic emission diagnostic system STsAD 16.03 (No. 18892-10 in the State Register) [11, 12] with a recording threshold of $5 \mu \mathrm{V}$. Four acoustic emission transducers with a bandwidth of $0.1-0.7 \mathrm{MHz}$ were installed in the corners of the sample at a distance of $10 \mathrm{~mm}$ from the edge. Coordinates of acoustic emission sources were determined using planar location algorithms based on the difference between times of arrival of the signals to the transducers, which form a rectangular piezo antenna.

\section{Experimental data and results}

The amplitude distribution of the signals (Fig. 2) is described by the exponential distribution law with an average amplitude of $20 \mu \mathrm{V}$ at the preamplifier input. The discrimination threshold $\mathrm{u}_{0}=5 \mu \mathrm{V}$ allows about $70 \%$ of the total number of signals to be recorded. Signals associated with processes at the top of the crack, whose amplitude is within a range of 100 to $800 \mu \mathrm{V}$ (significantly higher than the average) are identified in the flow. The share of these signals varies from 10 to $12 \%$, while the probability of such signals calculated for the exponential distribution does not exceed $0.1 \%$ 


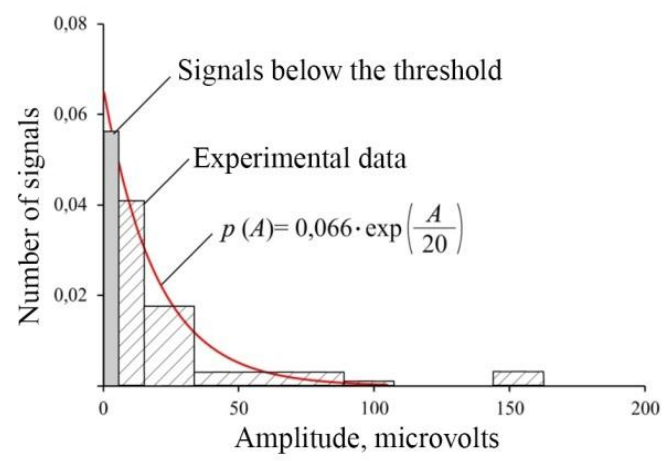

Fig. 2. Distribution of the relative number of acoustic emission signals by amplitude.

The amplitude distribution of the signals corresponds to the exponential distribution with an average amplitude at the preamplifier input equal to $20 \mu \mathrm{V}$. At the same time, groups of signals whose time interval substantially exceeds the average time between signals within the group are identified in the total flow of acoustic emission signals. In order to detect and identify the beginning and end of signal groups, it is proposed to use the ratio of time intervals $\mathrm{K}_{\mathrm{B}}$ and $\mathrm{K}_{\mathrm{E}}$, whose values indicate the beginning and end of the group, respectively (Fig. 3):

$$
\begin{aligned}
& K_{B}=n \cdot \frac{t_{m}-t_{m-1}}{t_{m+n}-t_{m}}, \\
& K_{E}=n \cdot \frac{t_{m+1}-t_{m}}{t_{m}-t_{m-n}},
\end{aligned}
$$

where $t_{m}$ is the recording time of the mth acoustic emission signal, $n$ is the number of signals for estimating the average value of the time interval. The critical ratio of time intervals between signals with a given significance level $\mathrm{q}$ for an arbitrary value $\mathrm{n}$ is determined by the formula:

$$
K_{c r}=n\left(\sqrt[n]{\frac{1}{q}}-1\right)
$$

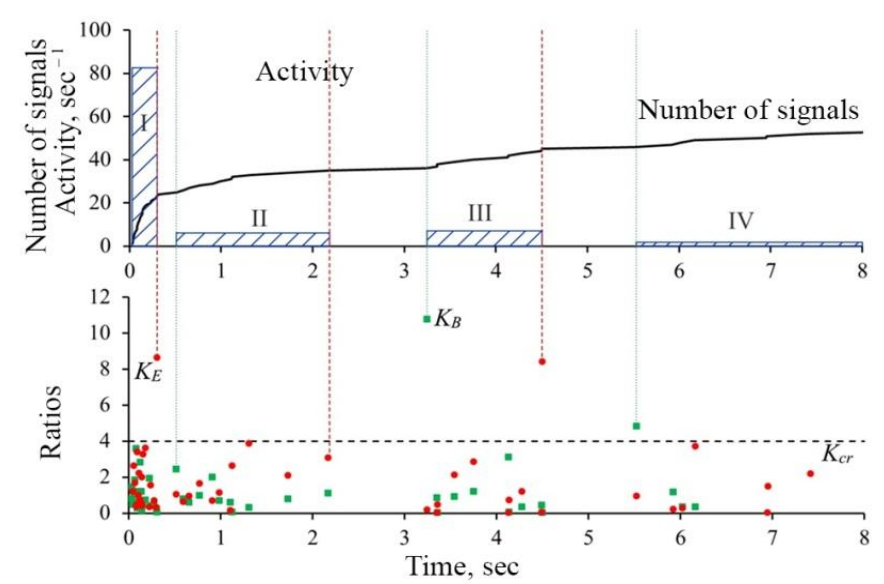

Fig. 3. Time dependence of the number of acoustic emission signals and the average activity of signal groups, identified by ratios of time intervals $\mathrm{K}_{\mathrm{B}}$ and $\mathrm{K}_{\mathrm{E}}$. 
The dynamic loading, implemented through an elastic impact on the surface of the monitored object, brings the object to the stress-strain state. Recorded events of acoustic emission are localized not only in the impact zone but also in a growing crack zone.

The impact loading of the cracked object causes a residual elastic deformation associated with the displacement of the crack edges in the form of longitudinal shear. This process is accompanied by the destruction of crack edges and produces discrete acoustic emission.

The recorded acoustic emission is a non-stationary process: signals are emitted in groups that significantly differ from each other in terms of activity (by 10-50 times). The time intervals between acoustic emission signals within a group are described by an exponential distribution. Based on the ratio of time intervals between signals to their average value, a method for detecting stationary signal groups has been proposed.

\section{Conclusion}

As a result of the studies described above, the authors have found a number of regularities that can be used to identify acoustic emission signals produced by destruction processes in the crack zone. The authors also developed the experimental scheme for studying processes caused by dynamic loading in objects made of brittle materials. The obtained results can be used to study behaviors of structural elements made of materials susceptible to brittle fracture.

\section{References}

1. V.V. Muravyev, L.N. Stepanova, A.E. Kareev, Defektoskopija [Russian Journal of Nondestructive Testing], 1, 63-68 (2003). (in Russian)

2. V.V. Muravyev, O.V. Muravyeva, Deformatsiya i razrushenie materialov [Deformation and destruction of materials], 1, 24-29, (2016). (in Russian)

3. L.N. Stepanova, E.Yu. Lebedev, A.E. Kareev, V.N. Chaplygin, S.A. Katarushkin, Russian Journal of Nondestructive Testing, 7, 455-461 (2004).

4. Z. Nazarchuk, Acoustic emission. Methodology and Application (Springer, 2017).

5. W. Hwang, S. Bae, J. Kim, S. Kang, N. Kwag, B. Lee, Nuclear Engineering and Technology, 47, 454-460 (2015).

6. P. Mazal, F. Vlasic, V. Koula, Procedia Engineering, 133, 379-388 (2015).

7. S. Sengupta, A.K. Datta, P. Topdar, Lat. Am. J. Solid Struct., 12, 8 (2015).

8. F. Qiu, G. Dai, Y. Zhang, Insight - Non-Destructive Testing and Condition, 59, 653358 (2017).

9. S.A. Bekher, Thesis of Candidate of sciences, Siberian Transport University, Novosibirsk, 2004 (in Russian)

10. S.A. Bekher, T.V. Sych, A.A. Popkov, Method of calibration of acoustic emission transducers, RU Patent 2650357 (2018).

11. GOST R ISO 22096-2015. Condition monitoring and diagnostics of machines. Acoustic emission method (Moscow, 2016). (in Russian)

12. GOST R 55047-2012. Technical diagnostics. Without standards calibration of equipment for measuring the stress-strain state of structural materials. General requirements (Moscow, 2017). (in Russian) 